\title{
A MIDIATIZAÇÃO DO ATIVISMO E OS ELE- MENTOS CONSTITUTIVOS E DE ANÁLISE DO CONCEITO DE COLETIVO MIDIÁTICO
}

\author{
MARIA CLARA AQUINO BITTENCOURT \\ UNIVERSIDADE DO VALE DO RIO DOS SINOS \\ SÃO LEOPOLDO, RIO GRANDE DO SUL, BRASIL \\ AQUINO.MARIACLARA@GMAIL.COM \\ CHRISTIAN GONZATTI \\ UNIVERSIDADE DO VALE DO RIO DOS SINOS \\ SÃO LEOPOLDO, RIO GRANDE DO SUL, BRASIL \\ CHRISTIANGONZATTI@GMAIL.COM
}

HTTP://DX.DOI.ORG/10.5902/2316882X26515 


\section{A MIDIATIZAÇÃO DO ATIVISMO E OS ELEMENTOS CONSTITUTIVOS E DE ANÁLISE DO CONCEITO DE COLETIVO MIDIÁTICO}

Resumo: $O$ texto apresenta o conceito de coletivo midiático, central no projeto de pesquisa que identifica transformações, elementos e continuidades do jornalismo digital. Os passos relatados no artigo mapeiam grupos e esboçam critérios iniciais de análise das fases posteriores da pesquisa, como um exercício de reconhecimento do campo.

Palavras-chave: jornalismo digital; midiatização do ativismo; coletivos midiáticos.

\section{LA MEDIATIZACIÓN DEL ACTIVISMO Y LOS ELEMENTOS CONSTI- TUTIVOS Y DE ANÁLISIS DEL CONCEPTO DE COLECTIVO DE MEIO}

Resumen: El texto presenta el concepto de colectivo mediático, central en el proyecto de investigación que identifica transformaciones, elementos y continuidades del periodismo digital. Los pasos relatados en el artículo asignan grupos y esbozan criterios iniciales de análisis de las fases posteriores de la investigación, como un ejercicio de reconocimiento del campo. Palabras clave: periodismo digital; mediatización del activismo; colectivos de medios

THE MEDIATIZATION OF ACTIVISM AND THE CONSTITUTIVE ELEMENTS AND ANALYSIS OF THE CONCEPT OF MEDIA COLLECTIVE

Abstract: This text presents the concept of media collective, central to the research project that identifies transformations, elements and continuities of digital journalism. The steps reported in the paper map groups and sketch initial criteria for analysis of the later phases of the research, as an exercise of field recognition.

Keywords: digital journalism; activism mediatization; collective media. 


\section{INTRODUÇÃO}

Este texto é parte de uma pesquisa que tem início em agosto de 2015 e que estuda produção e circulação de conteúdos por coletivos midiáticos em contexto de movimentos em rede (Scherer-Warren, 2006; Castells, 2012; Toret, 2012; Malini e Antoun, 2013). O principal objetivo do projeto é identificar transformações, elementos e continuidades do jornalismo digital num cenário em que interesses de movimentos sociais, cidadãos, ativistas e jornalistas estimulam diversas apropriações jornalísticas. Os dados aqui apresentados reúnem referencial teórico e critérios de observação para lidar com o corpus definido neste texto para mostrar o trabalho do grupo durante o processo de elaboração do conceito de coletivo midiático. Utilizamos como exemplo para ilustrar o conceito e os critérios de análise construídos, o coletivo midiático Mídia Ninja, pois é um dos grupos estudados no projeto que mais aciona dados e possibilidades de investigação acerca dos processos que nos interessam sobre produção e circulação de conteúdos acerca dos movimentos em rede.

O aporte teórico é construído a partir do conceito de midiatização (FAUSTO NETO, 2008; BRAGA, 2012; HAJRVARD, 2014) para pensar o entrelaçamento entre as noções de convergência midiática (JENKINS, 2008; AQUINO BITTENCOURT, 2012) e espalhamento (JENKINS, GREEN \& FORD, 2013). A reflexão sobre midiatização do ativismo e sobre produção e circulação de conteúdos sobre protestos guia a pesquisa pela expansão de apropriações midiáticas feitas por jornalistas, cidadãos, ativistas, movimentos e pela própria mídia de massa. Refletimos sobre a conjuntura de produção e circulação de conteúdos no cenário dos movimentos em rede e esboçamos um quadro de observação inicial, tentando captar, a partir de uma categorização inspirada em Arquilla e Ronfeldt (2001) e Malini e Antoun (2013), características e práticas de um coletivo selecionado para essa etapa inicial do projeto, que consideramos mais representativo do entendimento desenvolvido.

\section{O CONCEITO DE COLETIVO MIDIÁTICO}

A expressão tem origem quando de observações sobre as manifestações de junho de 2013, no Brasil, inicialmente contra o aumento da tarifa do transporte público e, posteriormente com uma lista de reivindicações ampliada. Naquele momento, alguns grupos, apropriando-se principal-

Rev.Cad.Comun. Santa Maria, v.22, n.1, art 3, p.60 de 78, jan/abr.2018 
mente sites de redes sociais e de dispositivos móveis de comunicação móvel iniciaram a cobrir atos de rua. As apropriações tecnológicas por esses grupos e a motivação de gerar conteúdo através de processos orientados por lógicas diferentes das empreendidas pela mídia de massa são duas características que compõem nosso entendimento sobre um coletivo midiático. É necessário, nesse caso, expor o que consideramos mídia de massa.

Autores como Beltrão (1972), que abordavam a comunicação massiva antes da popularização da internet, sugeriam que num modelo massivo as conversas são pautadas pelo que é veiculado nos meios, além da submissão aos poderes burocrático e técnico exercidos pelos detentores dos meios sobre produtores de conteúdos, o que acaba padronizando as mensagens. Num momento em que a internet já fazia parte do cotidiano de um número considerável de indivíduos, a característica da padronização novamente aparecia em abordagens sobre a comunicação massiva. Dizard Jr. (2000, p. 23), no início do século XXI, entendia a mídia de massa como "produtos de informação e entretenimento centralmente produzidos e padronizados, distribuídos a grandes públicos através de canais distintos". Para ele, as novas tecnologias não se adequavam a essa definição de massa, pois, por não possuírem uma fonte central de emissão, tinham capacidade de modificar essas condições. O desenvolvimento dessas tecnologias provocava uma corrosão dos estilos operacionais da mídia antiga pela nova, principalmente em função de mudanças no modelo de distribuição.

Os dois autores comentam características do modelo de massa baseado na detenção do poder sobre os meios, fortalecendo a concentração dos mecanismos de produção e a unilateralidade da distribuição. No entanto, são apontamentos feitos em momentos distantes do presente. Beltrão (1972) tece suas considerações numa época em que a internet estava dando seus primeiros passos, restrita ao campo militar e acadêmico. Dizard Jr. (2000) aborda o assunto com a internet já popularizada em certo sentido; recém iniciava a ser povoada com ferramentas de publicação de conteúdo de fácil manuseio, como os blogs, por exemplo. Em 2006, Jenkins (2006) fala em cultura da convergência, concluindo que se antes se pensava que as novas mídias tomariam o lugar das mídias antigas, o paradigma da convergência coloca mídias antigas e novas em convivência. Logo, mais do que pensar em substituição, entende-se o presente momento como um período de experimentação e transição, no qual o modelo de massa não é 
substituído, mas deixa de ser exclusivo para contracenar com novas práticas que destoam, e em alguns momentos nem tanto, de lógicas unidirecionais e padronizadas. Por mais que a internet permita a ocorrência de modelos e práticas fundamentados na horizontalidade da produção e da circulação, ainda assim atividades pautadas pela verticalidade de condutas acontecem mesmo no ambiente online. É o que acontece com alguns coletivos, como exposto adiante.

Diante de tais considerações, o conceito de coletivo midiático engloba grupos que através de sites redes sociais, plataformas digitais, aplicativos e dispositivos móveis de comunicação produzem e promovem o espalhamento de conteúdos sobre protestos decorrentes de mobilizações organizadas dentro e fora das redes digitais, e que buscam atuar de forma desvinculada da mídia de massa, com base na participação e na convergência, ainda que reproduzam lógicas massivas em seus processos de produção e circulação de conteúdos. São grupos que podem ou não participar da organização de protestos de rua. Sobre o caráter comercial, coletivos midiáticos não almejam o lucro, o que não os impede de estabelecer mecanismos de contribuição para a realização de atividades diversas, que envolvam a produção e circulação de conteúdos e a organização de mobilizações. Esses mecanismos variam entre o envio de quantias em dinheiro através de contas bancárias ou sistemas de pagamento online, venda de produtos e também projetos de crowdfunding para causas e ações mais específicas.

\section{MidiatizaÇÃo, CONVERGÊNCIA E ESPALHAMENTO COMO CON- CEITOS NORTEADORES}

Pautadas pela convergência e pelo espalhamento, iniciativas de coletivos midiáticos se apropriam da comunicação digital na tentativa de instituir e fortalecer novos formatos e dinâmicas para informar sobre as causas que defendem e os acontecimentos nas ruas, oriundos de mobilizações populares. A midiatização é o conceito de fundo que ampara nosso entendimento sobre essas apropriações pelos coletivos.

Para Braga (2012), a midiatização provoca situações indeterminadas e experimentações correlatas em função do atravessamento entre campos sociais específicos. Nesse sentido, a apropriação baseia o argumento de Fausto Neto (2008) sobre a disseminação de novos protocolos técnicos

Rev.Cad.Comun. Santa Maria, v.22, n.1, art 3, p.62 de 78, jan/abr.2018 
pela organização social; ele menciona a intensificação de processos que acabam transformando tecnologias em meios de produção, circulação e recepção de discursos. Devido a tais apropriações, a midiatização ultrapassa o domínio dos meios em si, conferindo novas dinâmicas à organização social. Hjarvard (2014) estuda a midiatização a partir do entendimento de que a influência da mídia vai além das sequências comunicativas entre atores e mensagens, ampliando seu espectro para a relação entre os meios e outras esferas sociais.

Quando falamos em midiatização do ativismo questionamos como coletivos midiáticos se apropriam das tecnologias para organizar e reportar ações e demais acontecimentos, sem mais depender de veículos de massa para alcançarem visibilidade. Essa midiatização do ativismo também implica no repensar sobre como a sociedade se relaciona com esse conteúdo e como a própria mídia tradicional enxerga, e se apropria ou não, de práticas baseadas na participação. Essa relação entre meios, sociedade e cultura é foco dos estudos de midiatização quando os meios, ao mesmo tempo em que modificam estruturalmente a cultura e a sociedade, também adquirem maior autoridade sobre a realidade e padrões de interação social (HJARVARD, 2014).

Através de um comparativo entre a noção de circulação e o contexto das audiências de massa, Jenkins, Green \& Ford (2013) falam sobre uma "mídia de espalhamento", que funciona a partir de um modelo híbrido de circulação ainda emergente, que mescla forças de cima e de baixo e que regem o compartilhamento do conteúdo através de culturas diversas e de formas mais participativas, pelas quais os consumidores criam, compartilham e remixam conteúdos midiáticos. As noções que regem essa ideia têm origem na discussão sobre circulação, e autores como o próprio Jenkins (2006), Bradshaw (2008), Recuero (2009), Zago (2009, 2010), entre outros, discutem práticas que provocam além da circulação, uma recirculação de informações, impactando diretamente no jornalismo digital. Esse modelo de espalhamento pressupõe a interligação de formatos diversos em um cenário marcado pelas relações entre diferentes meios, compondo um processo de convergência atrelado à efetivação deste modelo.

O conceito de convergência se destaca nos estudos sobre o jornalismo digital em meio à diversidade de apropriações tecnológicas, demandando uma atenção especial aos aspectos que o compõem. Aquino Bittencourt

Rev.Cad.Comun. Santa Maria, v.22, n.1, art 3, p.63 de 78, jan/abr.2018 
(2012) mapeia as origens do conceito com base na premissa de que aspectos técnicos, ainda que não possam ser ignorados, não podem ser determinantes para o seu entendimento. Assim, compreende o fenômeno como composto de categorias que podem ser analisadas a partir da relação entre diferentes meios de comunicação sempre levando em consideração as dimensões técnicas, sociais e culturais do processo de convergência.

\section{PRODUÇÃo E CIRCULAÇÃO DE CONTEÚdOS POR MOVIMENTOS EM REDE}

Ainda que a adoção de ferramentas de comunicação seja prática incorporada ao ativismo antes da internet, como lembra Tufte (2013), frisa que é a partir da Primavera Árabe que esses usos são ampliados. Para Scherer-Warren (2006), a partir da segunda metade do século XX, os movimentos sociais se diversificam e se complexificam, em função da globalização e da informatização da sociedade. Gohn (2010) indica que o uso de tecnologias digitais fortalece articulações e estratégias de visibilidade, reconfigurando formas de organização e de ações.

No Brasil, Malini e Antoun (2013) observam práticas de adoção da internet por movimentos sociais já há algum tempo, e refletem sobre a perda do monopólio pela mídia de massa sobre a narrativa dos fatos. Não se trata de um abandono completo da mídia convencional, mas do fortalecimento da mídia independente provocado pela diversidade de apropriações. Antoun e Malini (2010) elencam a atuação social, a mobilização e o engajamento como valores da rede para abordar a notícia como algo que escapa das mãos daqueles que antes detinham, de forma exclusiva, o poder de irradiar informação, e passa a se fazer presente em múltiplos lugares virtuais, os quais chamam de mídias de multidão. Toret (2012), ao estudar o movimento espanhol $15 \mathrm{M}$, identifica um sistema multicamadas, que confere sentido ao que ele entende como narrativa coletiva transmidiática. Trata-se da sobreposição entre rua e rede através das diferentes manifestações (de organização do movimento e de trocas informativas) que acontecem nesses espaços, reportando a rotina do movimento e o andamento das mobilizações. Nesse sentido, é importante ressaltar o papel que espaços abertos como o Twitter e plataformas de publicação de conteúdo como o Medium, por exemplo, entre outras, diferente do Facebook que funciona através de filtros de personalização (PARISER, 2012)

Rev.Cad.Comun. Santa Maria, v.22, n.1, art 3, p.64 de 78, jan/abr.2018 
possuem na atividade desses coletivos durante mobilizações e rotinas de ativismo. Tentativas de controle de tráfego e de centralização de fluxo de conteúdo afetam a produção e a circulação de informações desses grupos (AQUINO BITTENCOURT, 2015) que buscam reportar atos e protestos de rua. As barreiras impostas por limites e configurações de privacidade, por exemplo, impedem que os dados circulem de forma mais livre e acessível do que em sistemas que não impõem esquemas de limitação de visibilidade de conteúdos.

Diante desse panorama, a midiatização do ativismo se dá na medida em que cada vez mais a apropriação de tecnologias de comunicação fazem parte do cotidiano de movimentos em rede, como recupera Castells (2012). Nesse sentido, a apropriação se torna conceito central para pensar processos de produção e circulação. Ao liberar ativistas das amarras da mídia tradicional, abrindo-lhes oportunidades midiáticas (CAMMAERTS, 2013), o uso da internet e das tecnologias digitais na rotina de coletivos ilustra como a busca pela independência é motor desses processos de produção e circulação. O que não quer dizer, obviamente, que o trabalho desses coletivos seja livre de práticas baseadas em modelos unilaterais de comunicação. Entendemos que alguns possuem objetivos direcionados para a construção de novas práticas e modelos de produção, circulação e consumo de conteúdos, mas também que esses objetivos fazem parte de um processo de busca ainda em desenvolvimento, sujeito à hábitos e atitudes ainda presos a modelos anteriores, bem como secundários em alguns grupos, cujo foco principal é uma ou um conjunto de causas políticas.

\section{O COLETIVO OBSERVAdo e A DEFiniçÃo dos CRITÉrios DE ANÁLISE}

Para dar início ao projeto fizemos um levantamento sobre os protestos que iniciaram em junho de 2013 no Brasil. Diante da multiplicidade de grupos envolvidos na produção e circulação de conteúdo sobre os mais diversos temas e diante de vários atos e mobilizações espalhados pelo país, entendemos que, desde o final de 2014 e, principalmente, em função dos protestos de março de 2015, esse contexto propiciou uma polarização entre pessoas e movimentos a favor e contra o governo de Dilma Rousseff. A partir dessa polarização optamos por realizar um levantamento de coletivos midiáticos que estivessem produzindo e fazendo circular conte-

Rev.Cad.Comun. Santa Maria, v.22, n.1, art 3, p.65 de 78, jan/abr.2018 
údo a favor e contra o governo da presidente. Posteriormente, o projeto procedeu a um mapeamento dos coletivos, que foi realizado através das fanpages do Facebook, considerando que o site de rede social tem sido a principal ferramenta utilizada pelos grupos de maior representatividade que vem sendo observados desde o início da pesquisa. Neste momento definiu-se como recorte de coleta grupos que tivessem mais de 5 mil likes em suas fanpages, o que permitiu a identificação de uma rede de coletivos que recomendavam uns aos outros. Jornalistas Livres, RioNaRua, Democratize, R.U.A Foto Coletivo, BH nas Ruas, foram alguns dos coletivos que mais se destacaram pela intensidade das publicações. Ainda assim, muitos dos grupos observados deixaram de publicar já em 2013, sendo que em 2016 coletivos que mesmo tendo mais de 5 mil likes já não eram mais ativos em termos de produção. Nessa lista também apareceram grupos como o Movimento Brasil Livre (MBL) e o Vem pra Rua, que posteriormente foram excluídos do projeto pelo seu foco em atividades de mobilização político-partidária, com objetivos que destoavam do entendimento construído no projeto sobre o conceito de coletivo midiático.

Importante notificar aqui que no fechamento deste texto o processo de impeachment contra Dilma estava em andamento, de modo que um dos coletivos em observação que gerava grande quantidade de conteúdos em diferentes canais de comunicação neste momento, e também desde as primeiras observações, quando das manifestações de 2013, era o Mídia Ninja. Definiu-se no grupo que o coletivo era adequado para ilustrar o conceito gerado no âmbito do projeto, permitindo exemplificar os exercícios exploratórios e as atividades que permitiram a geração dos primeiros critérios de análise da pesquisa.

\subsection{A DEFINIÇÃO DOS CRITÉRIOS DE ANÁLISE}

Durante as leituras acerca de movimentos em rede, nos deparamos com um procedimento investigativo elaborado por Arquilla e Ronfeldt (2001) que consideramos útil aos nossos objetivos. No capítulo introdutório de Networks and Netwars: the future of terror, crime, and militancy, os autores reúnem aspectos sobre o conceito de netwar (guerra em rede) em que trabalhavam desde 1993, destacando dois aspectos: o fortalecimento das formas de organização em rede, que estaria favorecendo a migração de poder para atores não-estatais, com mais capacidade de se articular

Rev.Cad.Comun. Santa Maria, v.22, n.1, art 3, p.66 de 78, jan/abr.2018 
em redes multiorganizacionais; e a dependência da circulação de informação que a condução e os resultados dos conflitos da época já mantinham por causa do aprofundamento intenso da revolução da informação. Nesse sentido, o que apontavam era como os conflitos cada vez mais giravam em torno do conhecimento e do conceito de soft power, de Nye (1990)', de modo que cada vez mais operações de informação e gerenciamento de percepção baseavam medidas orientadas para a mídia, fosse com foco em atrair, desorientar ou coagir. Os autores referem-se aos comportamentos dos adversários envolvidos na guerra em rede, uma diversidade de atores responsáveis pela reformulação dessas dinâmicas, grande parte deles desvinculada do Estado. Assim, entendem que há um padrão que atravessa essa diversidade de atores, e que permite analisar as redes da guerra em rede. Esse padrão pode ser verificado pelo design organizacional, pelo nível narrativo da história que está sendo contada, pelo nível doutrinário a partir de um olhar para os métodos e estratégias de colaboração, pelo nível tecnológico referente aos sistemas de informação e pelo nível social, referente aos vínculos estabelecidos entre os envolvidos.

Recuperando os níveis de análise de Arquilla e Ronfeldt (2001), Malini e Antoun (2013, p. 71) compreendem o nível tecnológico como o "padrão e capacidade dos fluxos de informação e comunicação da rede e pelas tecnologias de suporte deles". O nível social compreende "o quão bem e de que modos os membros são pessoalmente conhecidos e conectados uns com os outros", sendo necessário identificar vínculos que assegurem a confiança e a lealdade entre os membros". Sobre o nível da doutrina, Malini e Antoun (2013, p. 71) entendem como aquilo que melhor orienta a organização em rede, "o que capacita aos seus membros agirem estratégica e taticamente sem precisar necessariamente se reportar a um comando central ou a um líder." Trata-se da aceitação mútua e coletiva entre os membros da rede de princípios e práticas condutoras, o que garante "coerência central ideacional, estratégica e operativa que permite a descentralização tática." Sobre o nível do design organizacional, Malini e Antoun (2013, p. 73) apontam como questionamentos a extensão em que "um ator ou grupo de atores está organizado como uma rede? O que faz a rede ter sua disposição?”. A questão que orienta o nível narrativo, para

\footnotetext{
1 Soft Power, em tradução livre Poder Brando. Termo criado por Joseph Nye,. Descreve como um corpo político é capaz de influenciar outros através de estratégias culturais e ou ideológicas.
}

Rev.Cad.Comun. Santa Maria, v.22, n.1, art 3, p.67 de 78, jan/abr.2018 
esses autores, é sobre o motivo de os membros de uma rede assumirem uma posição e permanecerem na mesma, isso por que as histórias são como elos que conectam e mantêm as pessoas unidas, além de possibilitarem um sentido de identidade e pertencimento. Segundo eles, "elas são capazes de dizer quem somos, porque estamos juntos e o que nos faz diferentes dos outros" (MALINI E ANTOUN, 2013, P. 74).

Dessa forma, enquanto Arquilla e Ronfeldt (2001) concentram suas análises na estrutura de redes ativistas e Malini e Antoun (2013) recuperam a historiografia e os conceitos envolvidos na rotina de ativistas e se debruçam sobre o enfrentamento entre a mídia corporativa e a mídia livre, apoiamo-nos nesses autores para pensar os processos de produção e circulação empreendidos por coletivos midiáticos com o objetivo de produzir informação sobre acontecimentos nas ruas ao mesmo tempo em que defendem uma causa, um ponto de vista. Estruturamos a análise dos coletivos a partir da seguinte interpretação dos níveis propostos por Arquilla e Ronfeldt (2001):

- Organização dos coletivos: referente ao nível do design, trata-se da maneira como o grupo é estruturado para produzir e fazer circular conteúdo. São analisadas a forma de manutenção dos coletivos e as dinâmicas de produção e circulação dos conteúdos disponibilizados nas ferramentas que utilizam.

- Formato e linguagem: identifica formatos e linguagens nas publicações, para pensar o nível narrativo empregado pelos coletivos. O conceito de convergência serve de aporte para a avaliação desse critério.

- Ações estratégicas: pensa o nível doutrinário dos coletivos, olhando para as estratégias focadas no aumento de seguidores e da visibilidade dos conteúdos, baseando-nos no conceito de espalhamento.

- Aparato tecnológico: compreender a base técnica dos coletivos faz parte do nível tecnológico. Aqui o foco é na identificação dos tipos de ferramentas e dispositivos utilizados e na descrição dos usos e apropriações desses aparatos, com base na noção de midiatização do ativismo.

- Relações, usos e apropriações: correspondendo ao nível social, esse critério volta-se para a relação entre os membros dos coletivos, e que gerenciam as ferramentas de comunicação utilizadas,

Rev.Cad.Comun. Santa Maria, v.22, n.1, art 3, p.68 de 78, jan/abr.2018 
com os consumidores dos conteúdos produzidos. Entender essas relações e identificar como esses consumidores se apropriam dos conteúdos é o objetivo desse critério.

\subsection{ANÁlise do COLETIVO}

Neste artigo desenvolvemos a análise do coletivo a partir dos critérios estabelecidos para entender sua atuação e desempenho em processos de produção e circulação de conteúdos. Os dados sobre números de seguidores são de agosto de 2016, , quando o Mídia Ninja contava com mais de 972 mil fãs na fanpage no Facebook e mais de 102 mil seguidores no Twitter. Seu posicionamento é considerado neste artigo como a favor da ex-presidente Dilma Rousseff, considerando os conteúdos publicados contra as manifestações convocadas a favor do impeachment, por exemplo, entre outras mensagens que demonstravam apoio ao governo daquele momento. O meio mais atualizado é o Facebook com publicações que, embora sejam esporádicas, são mais frequentes. No Twitter, constatamos que há intervalos de dias entre publicações próprias, quando não há nada de novo ou apenas retuítes de outros perfis...

\subsubsection{ORGANIZAÇÃO DO COLETIVO}

O Mídia Ninja (Narrativas Independentes, Jornalismo e Ação) se define como uma rede aberta e sem fins lucrativos. Baseia-se em colaboração para criação e compartilhamento de conteúdos na construção de reportagens, documentações e investigações não só no Brasil, mas em outros países também. Teoricamente qualquer pessoa pode ser um Ninja, produzindo e fazendo circular conteúdo pelo grupo - mas há uma negociação interna entre os coordenadores do coletivo e potenciais Ninjas. O coletivo se mantém através do investimento de seus colaboradores, com estrutura física e pessoal da rede de coletivos culturais Fora do Eixo e com o apoio de organizações internacionais interessadas em financiar novos agentes de comunicação. No site, declara-se independente de poderes econômicos e políticos. Esse formato não impede o grupo de explicitar seus posicionamentos sobre diferentes questões políticas, sociais e econômicas.

Na rede, possui perfis no Facebook, no Twitter, no Medium e no Instagram, além do site que funciona como um portal de notícias. A circulação dos conteúdos está condicionada a uma dinâmica de compartilhamento

Rev.Cad.Comun. Santa Maria, v.22, n.1, art 3, p.69 de 78, jan/abr.2018 
de informação entre as redes sociais, dependendo da atividade de seus colaboradores diretos e também de seu público, para o espalhamento dos conteúdos. As características das plataformas auxiliam nestas processualidades. O compartilhar do Facebook, o retuitar do Twitter e o recomendar do Medium são a essência do mecanismo que impulsiona a circulação das informações. Nesse sentido, além de pessoas interessadas em atuar produzindo conteúdo para o coletivo, o Mídia Ninja precisa de seguidores, pessoas que compartilhem e retuitem seus conteúdos para que ganhem visibilidade e cheguem a potenciais novos seguidores.

Em agosto de 2016 o Mídia Ninja contava com mais de 972 mil fãs na fanpage no Facebook e mais de 102 mil seguidores no Twitter. Seu posicionamento é considerado neste artigo como a favor da ex-presidente Dilma Rousseff, considerando os conteúdos publicados contra as manifestações convocadas a favor do impeachment, por exemplo, entre outras mensagens que demonstravam apoio ao governo daquele momento. $O$ meio mais atualizado é o Facebook com publicações que, embora sejam esporádicas, são mais frequentes. No Twitter, constatamos que há intervalos de dias entre publicações próprias, quando não há nada de novo ou apenas retuítes de outros perfis...

Ao entrarmos no site em dezembro de 2015, constatamos que o artigo mais recente era do dia 2 de outubro de 2015. Em 2016 o espaço foi retomado. Com cerca de 6.3 mil seguidores no Medium, o Mídia Ninja ainda explora pouco as possibilidades oferecidas pela ferramenta. Faz publicações esporádicas e pouco interage através de respostas aos textos publicados. A publicação no Medium acaba sendo apenas mais um suporte para disponibilização de conteúdo do coletivo, como uma vitrine, sem pouca interação entre os leitores e o coletivo, o que se percebe na baixa quantidade de recomendações na maior parte das publicações lá disponíveis - algumas delas sem nenhuma recomendação.

\subsubsection{FORMATO E LINGUAGEM}

Entendemos que a linguagem do Mídia Ninja apresenta especificidades em cada em meio. Os formatos das publicações seguem as possibilidades ofertadas por cada ferramenta, e em alguns casos não exploram todas as potencialidades interativas e técnicas. O site busca construir conversações complementares ao que é publicado em sites de redes sociais.

Rev.Cad.Comun. Santa Maria, v.22, n.1, art 3, p.70 de 78, jan/abr.2018 
A linguagem das matérias (Fig. 1) segue um tom jornalístico, de cobertura. Os textos são mais completos do que as publicações no Facebook e no Twitter, e buscam construir uma contextualização narrativa em torno dos casos que são relatados. Há título, linha de apoio, fotografias em destaque ao longo da matéria e subtítulos. No Facebook são compartilhados textos e imagens próprios e também de outras páginas, ao mesmo tempo em que são trazidas narrativas menos detalhadas que são complementadas por imagens e hashtags. O material do coletivo em outras ferramentas é compartilhado na fanpage e no Twitter, onde as hashtags e o compartilhamento de imagens surge como principal linguagem de comunicação com os públicos: há um texto descritivo, seguido de uma imagem que busca demonstrar um recorte de um acontecimento. O Instagram constrói narrativas com textos que se assemelham ao Twitter, embora as imagens, devido as estruturas do aplicativo, apareçam em destaque e, por isso, são mais atrativas esteticamente através de filtros e efeitos. No Medium a exploração de textos, fotos e vídeos é ampliada em alguns casos, mas há reprodução de conteúdos publicados no site do coletivo e também em veículos de comunicação, tornando o espaço um repositório ou um arquivo do que é publicado em outros espaços e por outros atores.

\title{
Frente Brasil Popular articula saída à esquerda para a crise
}

\begin{abstract}
por NINJA Segir

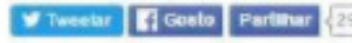

Lançada em Belo Horizonte no último sábado, frente agrega organizações de 22 estados e reúne principais movimentos tradicionais do pais.
\end{abstract}

Por Pedro Carrano e Rafael Tatemoto para Brasil de Fato

Fig. 1 - Cabeçalho de matéria no site

Fonte: site do Mídia Ninja

\subsubsection{AÇÕES ESTRATÉGICAS}

Uma das principais estratégias para promover o espalhamento e aumentar a visibilidade dos conteúdos do Mídia Ninja, além das compartilhamentos via Facebook, retweets pelo Twitter e recomendações no Medium, é a motorização dos conteúdos através de hashtags (Fig. 2). No Facebook atores sociais são convocados para participarem das narrativas e da construção dos acontecimentos a partir da utilização de hashtags, como \#Fora-

Rev.Cad.Comun. Santa Maria, v.22, n.1, art 3, p.71 de 78, jan/abr.2018 
Cunha, \#VemPelaDemocracia, entre outras. O uso, no entanto, não é feito em todas as publicações, além de que algumas hashtags não auxiliarem adequadamente na indexação de informações, por utilizarem palavras ou expressões muito específicas e particulares como, por exemplo, \#FelizNatalSemCunha ou \#VergonhaAlheia. No Twitter e no Instagram também aparecem, mas não há um posicionamento político evidente através delas, como no Facebook. No portal de notícias, há, no layout da página, uma área para colaboração: é possível fazer um cadastro e desenvolver artigos tornando-se, como o site diz, um Mídia Ninja. Não verificamos os detalhes desse processo, no entanto. Também é possível o financiamento do coletivo através de doações que, como eles colocam, não visam publicidade nem inserção no mercado, pois reconhecem a importância da inovação e do combate aos interesses corporativos dentro e fora das redações. No Medium o uso das hashtags não é frequente e em alguns casos levam para debates promovidos pelo coletivo em grupos no Telegram, aplicativo para troca de mensagens via celular. Nesses casos, mais do que organizar conteúdo, o objetivo talvez seja o de estimular a discussão em torno dos temas levantados nas publicações.

NINJA

"Não será fácil chegar ao poder na marra! Para chegar ao poder tem que ganhar nas urnas." Tico Santa Cruz esteve hoje na Câmara, acompanhado de dezenas de artistas e intelectuais, após se reunirem com a presidenta Dilma para expressar seu apoio contra o golpe.

Leia a Carta ao Brasil e assine também contra o golpe: http://goo.gl/6CQbZg

\#NaoVaiTerGolpe

\#ForaCunha

Curtir - Comentar - Compartilhar - 17 de dezembro de 2015

Tico Santa Cruz e outras 1.616 pessoas curtiram isso. Principais comentários c) 1.035 compartilhamentos

Fig. 2 - Publicação do Mídia Ninja Fonte: Facebook

Rev.Cad.Comun. Santa Maria, v.22, n.1, art 3, p.72 de 78, jan/abr.2018 


\subsubsection{APARATO TECNOLÓGICO}

O aparato tecnológico do Mídia Ninja engloba dispositivos móveis, importantes para as coberturas nas ruas. A partir das características já percebidas, constatam-se algumas particularidades relacionadas ao formato que resultam da apropriação desse aparato, como imagens produzidas, muitas vezes, com boa qualidade, o que leva a crer no uso de câmeras de celulares com alta resolução ou na utilização de câmeras digitais. Outro movimento, principalmente através do Instagram, é a utilização de filtros e recortes de imagem para melhorar a qualidade e a estética dos conteúdos (Fig. 3). Assim, há uma preocupação com o conteúdo imagético que é consumida pelo uso de aplicativos. No Facebook, existem imagens que, aparentemente, foram construídas em softwares de edição. O mesmo cuidado com as imagens aparece no site e no Medium. Nos acontecimentos retratados nas mídias analisadas, algumas vezes surgem vídeos que buscam contribuir para a construção da narrativa, o que nos mostra novamente que esse aparato têm um papel determinante para a construção de conteúdos pelo Mídia Ninja.

2. midianinja

$10 w$
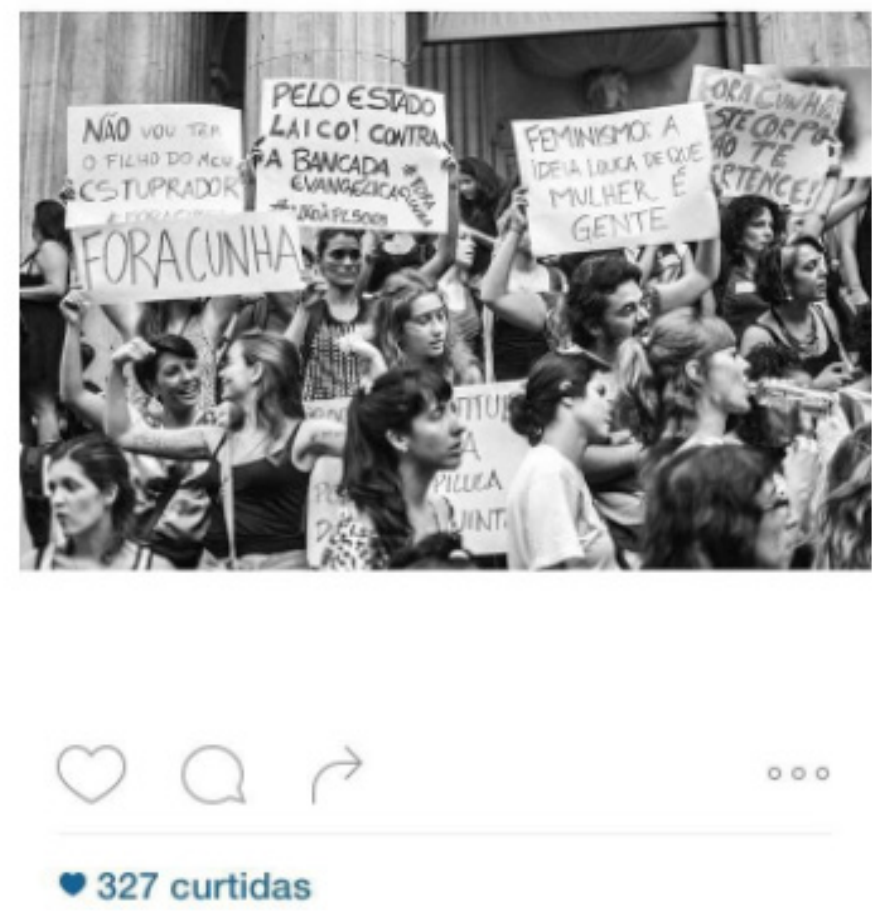

Fig. 3 - Mídia Ninja no Instagram

Fonte: Instagram

Rev.Cad.Comun. Santa Maria, v.22, n.1, art 3, p.73 de 78, jan/abr.2018 


\title{
5.2.5 RELAÇÕES, USOS E APROPRIAÇÕES
}

A interação entre o coletivo e seus seguidores é pouco perceptível nas ferramentas analisadas. Com isso, entendemos que o Mídia Ninja não se relaciona visivelmente com os públicos que os acompanham. Não há respostas frequentes a comentários em nenhuma das redes sociais. No entanto, o debate através da área de comentários no Facebook possibilita visualizar questões sociais que entram em pauta através de diferentes perspectivas expostas: um ator $x$ comenta algo, um outro ator y concorda ou discorda e a conversação se desenvolve ali. Há, também, em publicações com muitos comentários, termos que sugerem um posicionamento político dos públicos do Mídia Ninja, como, por exemplo, a utilização da palavra "coxinha" para se referir às pessoas que apoiam o governo de partidos e políticos específicos, como o PSDB. Os compartilhamentos das imagens e textos utilizam, em sua maioria, as hashtags levantadas pelo coletivo midiático. No Twitter, o Mídia Ninja retuita publicações que trazem os acontecimentos e, mais uma vez, as hashtags que são utilizadas funcionam como filtro de relevância. O potencial de discussão oferecido pelo Medium aravés dos destaques e comentários ao longo do texto são ignorados pelo coletivo. A própria carência de recomendações das publicações (Fig. 4) naquele espaço deflagra a pouca exploração do Medium como canal de relacionamento com os seguidores.

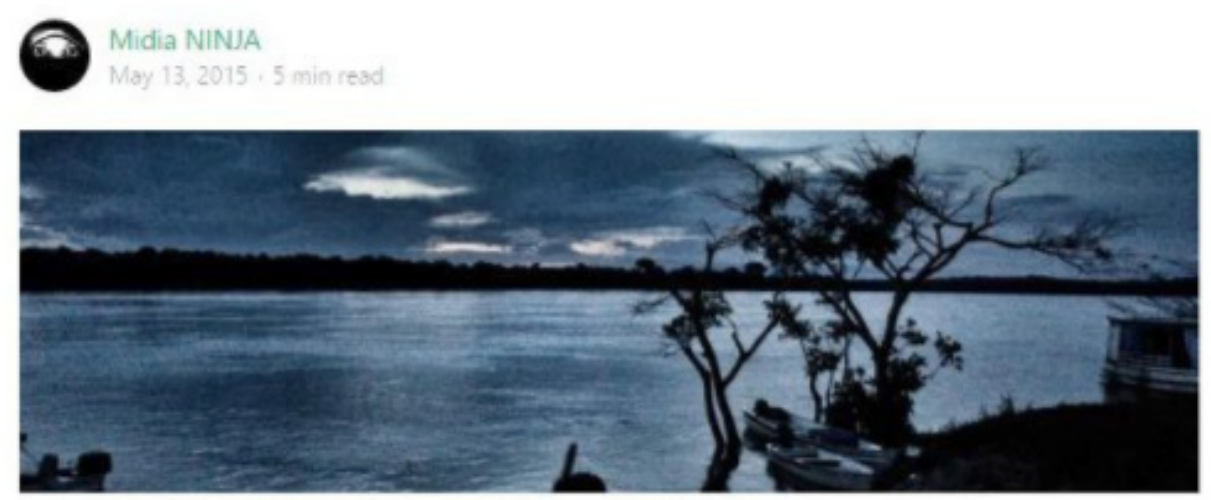

\section{Outros Belo Monte's}

\begin{abstract}
Na região da bacia do Tapajós_-entre os estados do Pará e Mato Grosso -estão sendo planejadas a construção de 29 Usinas...
\end{abstract}

Fig. 4 - Publicação sem recomendação do Mídia Ninja no Medium Fonte: Medium

Rev.Cad.Comun. Santa Maria, v.22, n.1, art 3, p.74 de 78, jan/abr.2018 


\section{CONSIDERAÇÕES FINAIS}

O Mídia Ninja atua com notável visibilidade, o que provoca reflexão sobre a noção de jornalismo, em função de seu foco permanecer, ainda que de forma menos explícita, no trabalho pela cobertura de forma diferenciada da mídia de massa. A partir das manifestações de 2013 no Brasil, se fortaleceu e ganhou representatividade no cenário da comunicação alternativa, deflagrando um fazer jornalístico que entrou em choque com práticas de massa tradicionais: enquanto havia a cobertura habitual, em grandes telejornais, por exemplo, o Mídia Ninja passou a cobrir os protestos em sites de redes sociais, através de textos, vídeos e imagens, entrando na cena midiática instantaneamente. Na prática, enxergamos algumas limitações desses ideais de participação e colaboração, assim como notamos que em determinados momentos o Mídia Mídia Ninja, assim como outros grupos acabam se fortalecendo mais como movimentos ativistas do que coletivos midiáticos. Vai depender das pautas a serem defendidas. O fato é que o que serve como força motriz para embasar a definição do conceito de coletivo midiático é o objetivo de produzir e colocar em circulação conteúdos que abordem os acontecimentos nas ruas acerca das questões políticas e sociais sobre o país, questões marginalizadas pela mídia de massa e que sejam, ou ao menos haja esforço para tal, pensadas de formadas diversas do modelo distributivo, e já esgotado, que exclui a participação e o envolvimento do pólo consumidor dos conteúdos.

O corpo social que compõe o Mídia Mídia Ninja não somente visualiza as publicações, mas pode vir a fazer parte da sua construção e é capaz, através dos sites de redes sociais, de participar mais visivelmente nos debates e na construção de uma pauta em mutação. Diferente do modelo de massa, as atividades de comunicação de coletivos midiáticos mostram que uma informação pode estender-se através de uma mensagem no Twitter, um vídeo no Facebook, uma imagem no Instagram, um texto no Medium e atravessar todos esses canais, deflagrando ainda mais o papel da circulação no atual momento do jornalismo através das internet. As limitações denunciam ao apego a práticas ainda bastante presentes do campo da comunicação, ainda que em rede, de forma que para o jornalismo digital essas permanências ainda demandam um exercício diário de reconfiguração que aproveite as oportunidades midiáticas que surgem tanto pelo desenvolvimento da tecnologia quanto das apropriações da diversidade dispositivos de comunicação digital. E em rede.

Rev.Cad.Comun. Santa Maria, v.22, n.1, art 3, p.75 de 78, jan/abr.2018 
CADERNOS DE COMUNICAÇÃO

UNIVERSIDADE FEDERAL DE SANTA MARIA

REFERÊNCIAS

ANTOUN, H.; MALINI, F. (2010) Ontologia da liberdade na rede: a guerra das narrativas na internet e a luta social na democracia. Revista FAMECOS (Impresso), v. 17, p. 286294.

AQUINO BITTENCOURT, M.C. (2012) Convergência entre televisão e web: proposta de categorização analítica. Tese de Doutorado. Programa de Pós-Graduação em Comunicação e Informação. Universidade Federal do Rio Grande do Sul. Disponível: http:// goo.gl/bbzhJ6 Acesso: 13/01/16.

AQUINO BITTENCOURT, M.C.

ARQUILLA, J.; RONFELDT, D. (2001) Networks and Netwars: The Future of Terror, Crime, and Militancy. Rand Corporation. Disponível:

http://goo.gl//6RGil Acesso: 19/01/16

BELTRÃO, L. (1972). Sociedade de massa: comunicação e literatura. Editora Vozes: Petrópolis.

BRADSHAW, P. (2008) News Distribution in a new media world. Online Journalism Blogs, 2 jan. Disponível: http://goo.gl/9DL5XD. Acesso: 19/01/16

BRAGA, J. L. (2012) Uma teoria tentativa. Revista da Associação Nacional dos Programas de Pós-Graduação em Comunicação, Brasília, v. 15, n. 3, set.-dez.. Disponível: http://goo.gl/dw1QOJ Acesso: 13/01/16

CAMMAERTS, B. (2013) Lógicas de protesto e a estrutura de oportunidade de mediação. Matrizes - Revista do Programa de Pós-Graduação em Ciências da Comunicação da Universidade de São Paulo, ano 7, n. 2, p. 13-36, jul./dez.

CASTELLS, M. (2012) Networks of Outrage and Hope - Social Movements in the Internet Age.Cambridge: Polity Press, 2012.

DIZARD JR. W. (2000) A Nova Mídia. Jorge Zahar Editor: Rio de Janeiro.

FAUSTO NETO, A. (2008) Fragmentos de uma analítica da midiatização. Revista Matrizes, n. 2, abril. Disponível:http://goo.gl/WnpTzB .Acesso: 13/01/16

GOHN, M. G. M. (2010) Movimentos sociais e redes de mobilização civis no Brasil contemporâneo. Petrópolis: Vozes.

Rev.Cad.Comun. Santa Maria, v.22, n.1, art 3, p.76 de 78, jan/abr.2018 
HJARVARD, S. (2014). A midiatização da cultura e da sociedade. São Leopoldo : Editora Unisinos.

JENKINS, H. (2006). Convergence Culture: Where Old and New Media Collide. NYU: Press.

JENKINS, H.; FORD, S.; GREEN, J. (2013) Spreadable media: creating value and meaning in a networked culture. New York University.

MALINI, F.; ANTOUN, H. (2013) @internet e \#rua: ciberativismo e mobilização nas redes sociais. Editora Sulina: Porto Alegre.

PARISER, Eli. O Filtro Invisível: o que a internet está escondendo de você. Rio de Janeiro: Zahar, 2012.

RECUERO, R. (2009) Redes sociais na Internet, difusão de informação e jornalismo: elementos para discussão. In: SOSTER, D.A.;SILVA, F.F. (Orgs.). Metamorfoses jornalísticas 2: a reconfiguração da forma. Santa Cruz do Sul: EDUNISC, p. 37-55.Disponível: http://goo.gl/XGqHWp Acesso: 13/01/16

SCHERER-WARREN, I. (2006). Das mobilizações às redes de movimentos sociais. In: Sociedade e Estado. Brasília. V. 21. N. 1. P. 190-130. Jan/abr. Disponível: http://goo.gl/ XTL5bj Acesso: 13/01/16

TORET, J. (2012) Una mirada tecnopolítica sobre los primeros dias del \#15M. In: Comunicación y Sociedad Civil. 2012. http://civilsc.net/node/14 Acesso: 13/01/16

TUFTE, T.(2013). O renascimento da Comunicação para a transformação social - Redefinindo a disciplina e a prática depois da 'Primavera Árabe'. In: Intercom - RBCC. São Paulo, v.36, n.2, p. 61-90, jul./dez.

ZAGO, G. (2009). Informações jornalísticas no Twitter: redes sociais e filtros de informações. In: III Simpósio da ABCiber, São Paulo. Anais.

ZAGO, G. ( 2010). Circulação jornalística no Twitter: apontamentos para discussão. VIII Encontro Nacional de Pesquisadores em Jornalismo. Universidade Federal do Maranhão, São Luís. 


\section{Maria Clara Aquino Bittencourt}

Doutora e mestre em Comunicação e Informação pelo Programa de Pós-Graduação em Comunicação e Informação da Universidade Federal do Rio Grande do Sul, com estágio pós-doutoral do Programa de Pós-Graduação em Ciências da Comunicação da Universidade do Vale do Rio dos Sinos (UNISINOS). Pesquisadora e professora do Programa de Pós-Graduação em Ciências da Comunicação da Unisinos.

E-mail: aquino.mariaclara@gmail.com

\section{Christian Gonzatti}

Mestrando do Programa de Pós-Graduação em Ciências da Comunicação da Universidade do Vale do Rio dos Sinos. E-mail: tainanrios@gmail.com

RECEBIDO EM: 04/04/2017

ACEITO EM: 04/06/2017 